\title{
ESTUDIO DE GENERACIÓN DE RESIDUOS ESPECIALES EN LA CONSTRUCCIÓN DEL FRACCIONAMIENTO PORTAL DE ROMANZA EN HERMOSILLO, SONORA
}

\author{
Study of generation of special residues in the construction of \\ the fractionation portal of romanza in hermosillo, sonora
}

EPISTEMUS

ISSN: 2007-8196 (electrónico)

ISSN: 2007-4530 (impresa)

Israel Miranda Pasos ${ }^{1}$

Ana Cecilia Borbón Almada 2

Jesús Fernando García Arvizu 3

Jesús Quintana Pacheco 4

Elsa Elizabeth Morales Morales 5

Gilberto Rivera Andrade 6

Recibido: 03 de marzo de 2015,

Aceptado: 12 de mayo de 2016

Autor de Correspondencia:

Dr. Israel Miranda Pasos

Correo: imiranda@dicym.uson.mx

\section{Resumen}

Los residuos sólidos municipales (RSM) urbanos provienen de diferentes fuentes de generación como viviendas, comercios, tiendas de conveniencia, supermercados, parques, construcción de obra civil, entre otras. Esta última fuente es el sector que genera una importante cantidad de residuos clasificados como De Manejo Especial según la norma Mexicana NOM-161-SEMARNAT-2011, por lo que no deben ser depositados en rellenos sanitarios municipales.

En la ciudad de Hermosillo, Sonora, los residuos de construcción comienzan a ser un serio problema, por lo que este trabajo intenta participar en su solución. Se realizó una medición piloto en el Fraccionamiento Portal de Romanza con construcción del tipo de interés social, con la finalidad de obtener información preliminar técnica que permita determinar su impacto en términos de generación, manejo y costo.

Palabras clave: residuo, desperdicio, manejo especial, generación, impacto ambiental.

\section{Abstract}

Urban municipal solid waste (MSW) from different generation sources such as homes, shops, convenience stores, supermarkets, parks, construction of civil works, among others. The latter is the industry source that generates a significant amount of waste classified as Special Management, according to the Mexican standard NOM -161-SEMARNAT-2011, so that should not be disposed in municipal landfills.

In the city of Hermosillo, Sonora, construction waste is becoming a serious problem, so this paper attempts to participate in its solution from a pilot measurement of the neighborhood Portal Romanza, with construction of the type of social house, in order to obtain preliminary technical information to assess their impact in terms of generation, handling and cost.

Keywords: residue, waste, special handling, generation, environmental impact.

Correo: imiranda@dicym.uson.mx 1 


\section{INTRODUCCIÓN}

La generación de residuos en las ciudades es un problema que aqueja a las sociedades actuales a nivel mundial, por lo que México no es la excepción. Según el Instituto Nacional de Ecología, en el año de 1964, se iniciaron en la ciudad de México los programas de recolección y disposición de Residuos Sólidos Municipales (RSM), así como la aplicación de métodos y técnicas de ingeniería para su manejo y tratamiento. (INE, 2013).

Los RSM urbanos tienen diferentes fuentes de generación, las casas habitación, comercios, tiendas de conveniencia, supermercados, parques y construcción. Es esta última la que genera residuos de Manejo Especial, que son producto de la edificación de obra civil. El INE clasifica los RSM por la fuente, su origen específico y por el tipo de residuo. Tomando en cuenta la clasificación según la fuente, el sector de la construcción-demolición es una de ellas.

Los residuos generados por el sector de la construcción son clasificados como Residuos de Manejo Especial por la norma NOM-161-SEMARNAT-2011. En su anexo Listado de Residuos de Manejo Especial fracción VII y en la Ley General para la Prevención y Gestión Integral de los Residuos, se definen como "aquellos generados en los procesos productivos, que no reúnen las características para ser considerados como peligrosos o como residuos sólidos urbanos, o que son producidos por grandes generadores de residuos sólidos urbanos".

En la actualidad, la alta demanda de obra civil es más que suficiente para que se estén generando cantidades considerables de residuos porque la construcción es tan masiva que no se requiere esperar a que un pueblo se conviertan en ruinas o sean devastados.

La generación de residuos en el sector de la construcción se produce por dos actividades principales: la obra nueva y la deconstrucción-demolición. Los residuos pueden tener diferentes orígenes; es decir, dependiendo de la etapa de construcción será el tipo residuo: en trazo y limpia se genera residuo orgánico e inorgánico (flora y suelo); en cimentación se genera acero, concreto, madera, entre otros. Así, cada etapa tiene sus residuos característicos.

Los impactos asociados a los residuos son:

- Vertidos incontrolados.

- El transporte de los residuos al vertedero y/o centros de acopio.

- La no reutilización de residuos.

Para disminuir los impactos, es necesario que haya sistemas eficaces de gestión de residuos que contemplen:

- La minimización en el uso de materias y recursos, principalmente en aquellos en los que se dificulta su reutilización o reciclaje.

- La reducción de los residuos; el mejor rendimiento de los materiales y productos; evitar tener inventarios en exceso para que estos no se conviertan en residuos; etcétera.

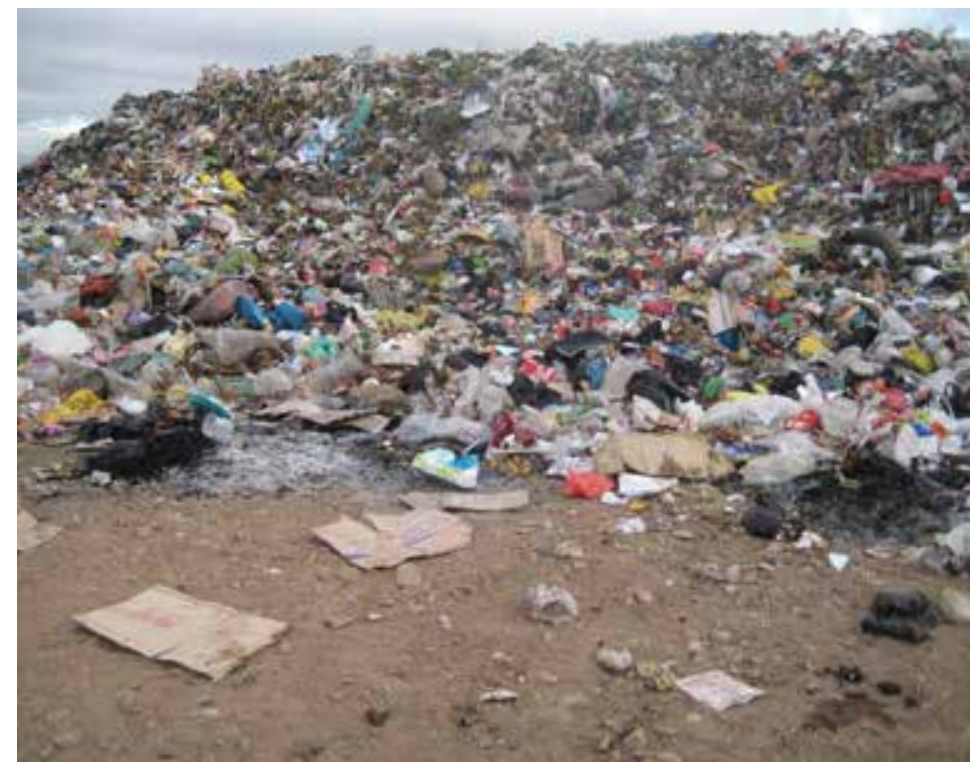

- El reciclado de residuos como los morteros para enjarres y el pegado de mampostería que puedan remezclarse para su mismo uso.

- La recuperación de energía al mandar los productos que son combustibles a las empresas que lo utilicen como fuente de energía.

- La reducción al mínimo de la cantidad de residuos y/o desperdicios a vertederos.

En la actualidad, los sistemas productivos fomentan el consumismo, lo cual tiene como consecuencia el hábito de usar y tirar. Por esta razón, debe redirigirse esta actitud hacia adquirir lo que realmente se necesita (reducir), seguido de fomentar la reutilización y el reciclaje (5).

En específico, en la ciudad de Hermosillo, Sonora, se generan residuos sólidos municipales, los cuales están cuantificados por subproductos. Es uno de ellos el sector de la construcción. La cantidad de generación de este sector no se tiene cuantificado por el Programa de Desarrollo Urbano Municipal del 2007, en parte porque las compañías constructoras y/o contratistas no reportan los residuos de la construcción; es decir, disponen de ellos mediante el vertido en áreas donde se requiere rellenar y/o nivelar terrenos o los depositan directamente en tiraderos a cielo abierto. En la ciudad se tenían contabilizados 25 de éstos en el 2005, donde el volumen de reciclados de residuos apenas era del $4.7 \%$ (4).

Atendiendo la problemática de no contar con la cuantificación de los residuos y/o desperdicios generados por el sector de la construcción, se realiza el presente estudio preliminar con el objetivo de cuantificar residuos y desperdicios más comunes de un frente de 12 viviendas de interés social, así como su impacto económico.

\section{SITIO DE ESTUDIO}

Las viviendas analizadas se ubican en el fraccionamiento Portal de Romanza, localizado al norte de la ciudad de Hermosillo (Figura 1). Las casas se construyeron a base de 


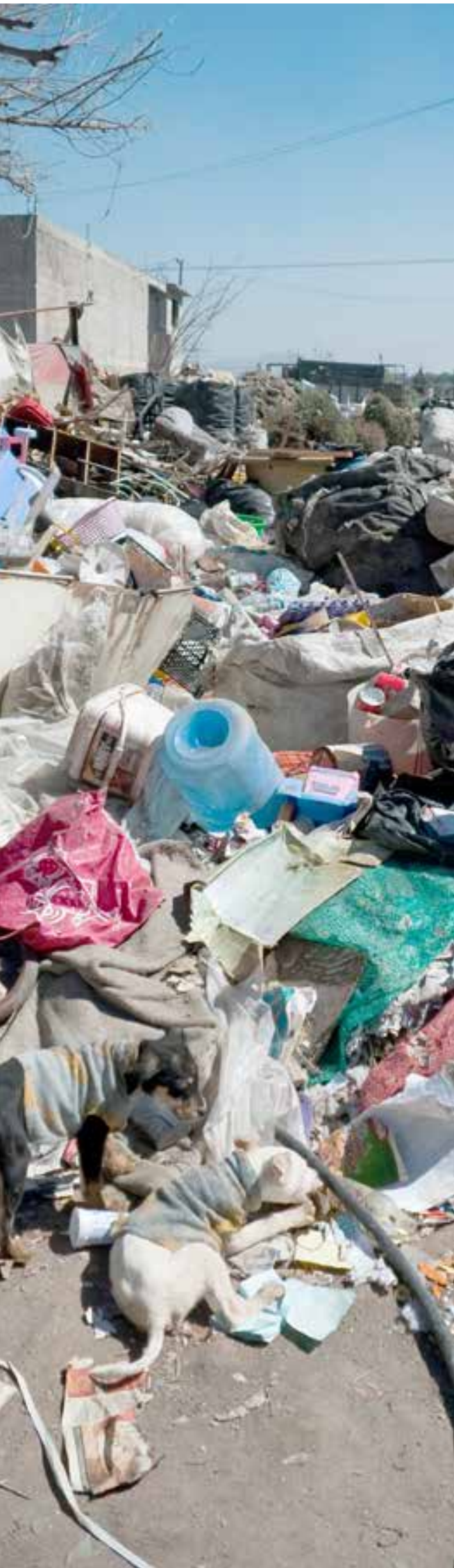

losa de cimentación de concreto armado, muros a base de bloque de mortero vibrocomprimido pegado con mortero a base de cemento-cal-arena, dalas y castillos ahogados con concreto, losa a base de vigueta y casetón con capa de compresión de $4 \mathrm{~cm}$ de espesor y acabados texturizados.

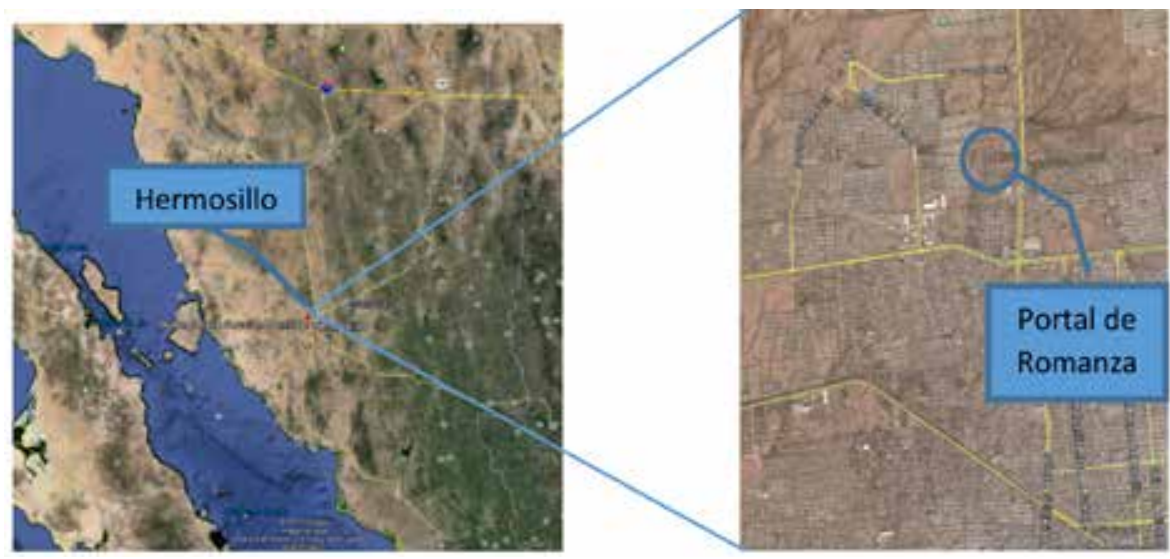

Figura 1. Localización del fraccionamiento Romanza hacia el norte de Hermosillo.

\section{DESARROLLO}

Se establecieron diferentes etapas en el proyecto para un mejor control y evaluación del avance. Las etapas que se llevaron a cabo son:

\section{Ubicación de viviendas}

Se seleccionaron las casas de las que se midieron los materiales de desperdicio y residuos. Las casas seleccionadas se ubican en la manzana 837 del lote 14 al 25, siendo un total de 12 viviendas de $46.108 \mathrm{~m}^{2}$ de construcción cada una.
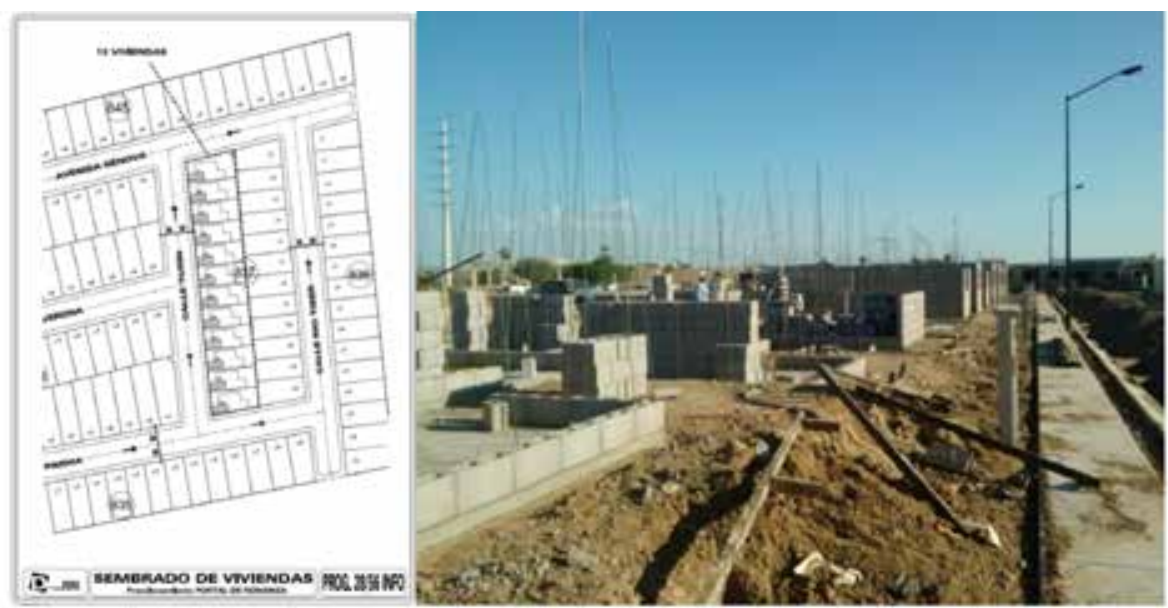

Figura 2. Localización del área de estudio dentro del fraccionamiento.

\section{Definición de desperdicios de materiales}

Los residuos y/o desperdicios seleccionados para ser medidos son cinco y se definieron por su origen de la siguiente manera:

A) Residuo de concreto: Material generado por la fabricación, vertido, colocación y acabado de elementos de concreto o por la demolición de elementos a base de concreto. 


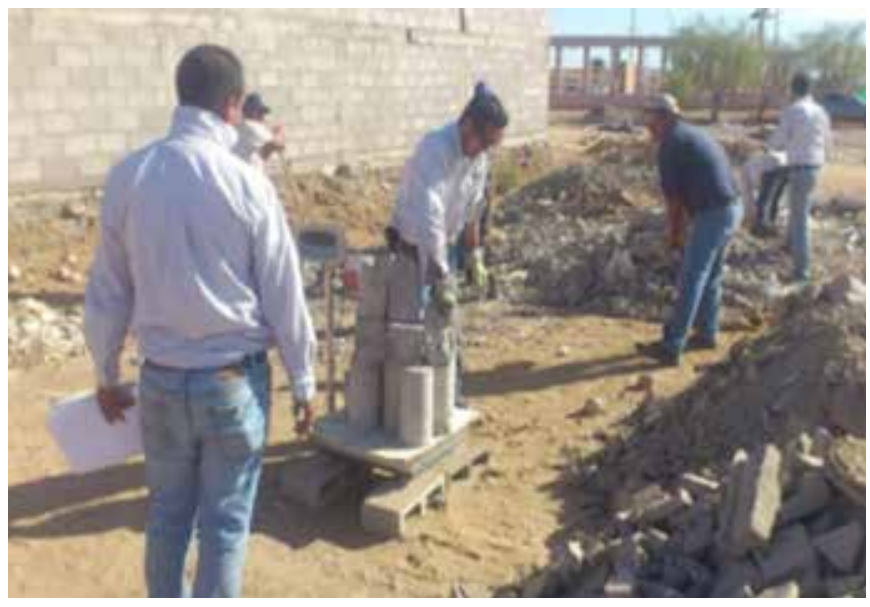

Figura 3. Concretos.

B) Residuo de mortero: Material generado por la fabricación, transporte, colocación, desperdicio o demolición de elementos a base de mortero.

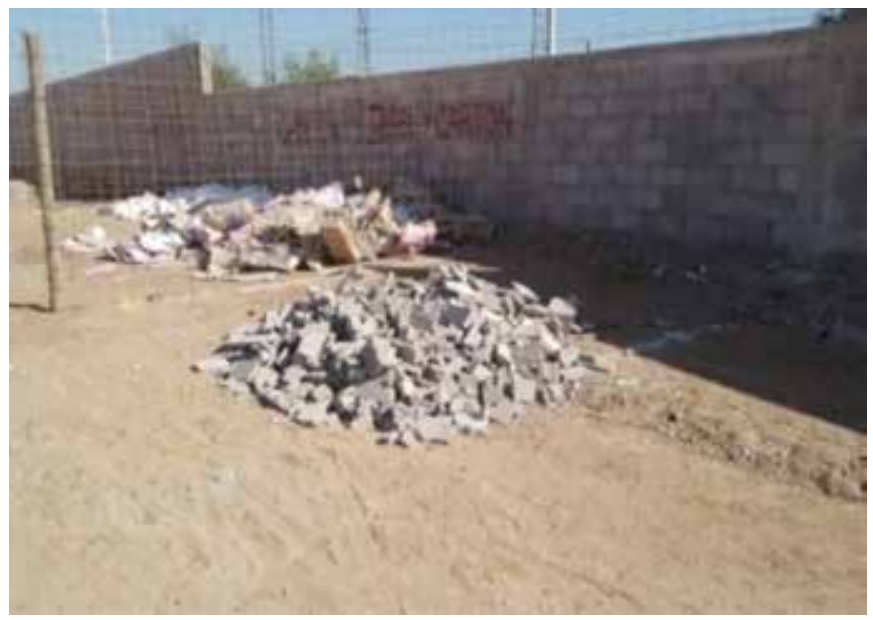

Figura 4. Recolección de mortero.

C) Residuo de block: Material generado por la fabricación, manejo y colocación de block.

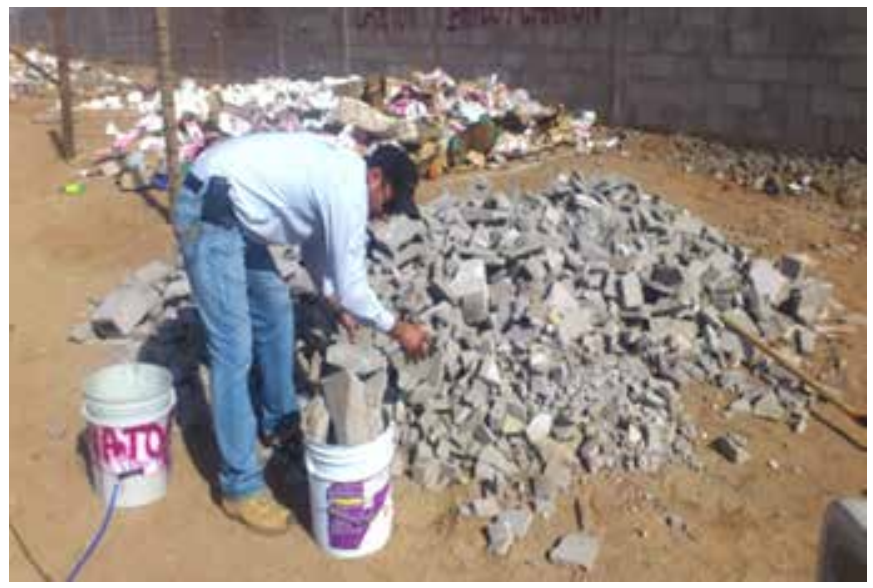

Figura 5. Recolección de block.
D) Residuo de plásticos-poliducto naranja: Material producto del corte y/o desperdicio, así como de la actividad de demolición-deconstrucción.

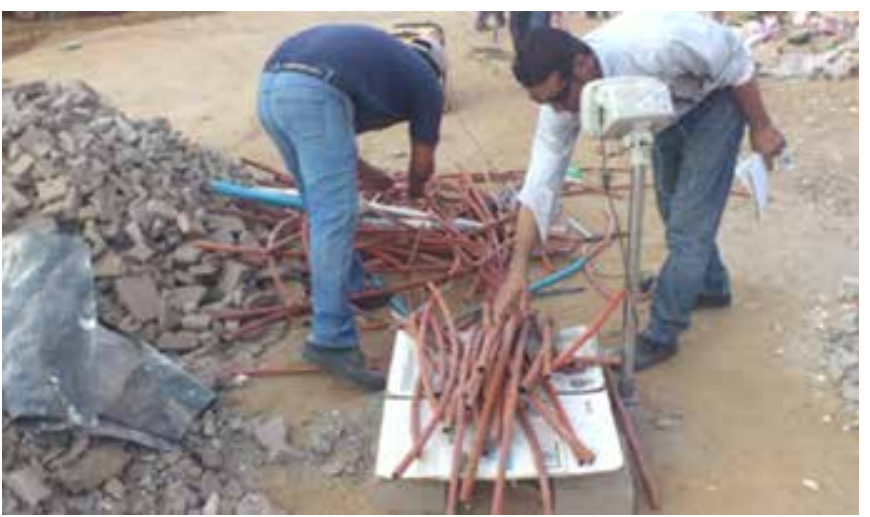

Figura 6. Plástico-poliducto.

E) Residuo de cartón-papel: Material reciclable producto de embalajes, sacos de envoltura de cementantes, cerámicos, entre otros.

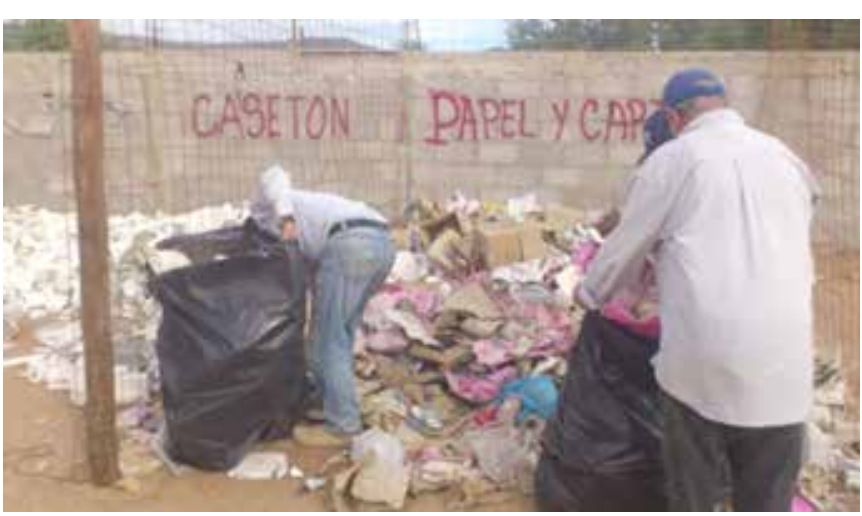

Figura 7. Cartón y papel.

\section{Acopio}

Los materiales recolectados se depositaron en áreas reservadas para cada tipo con el fin de llevar un control de ellos. La ubicación de los depósitos es en áreas cercanas al frente de obra para evitar que estos sean dispuestos en lugares diferentes (Figura 7).

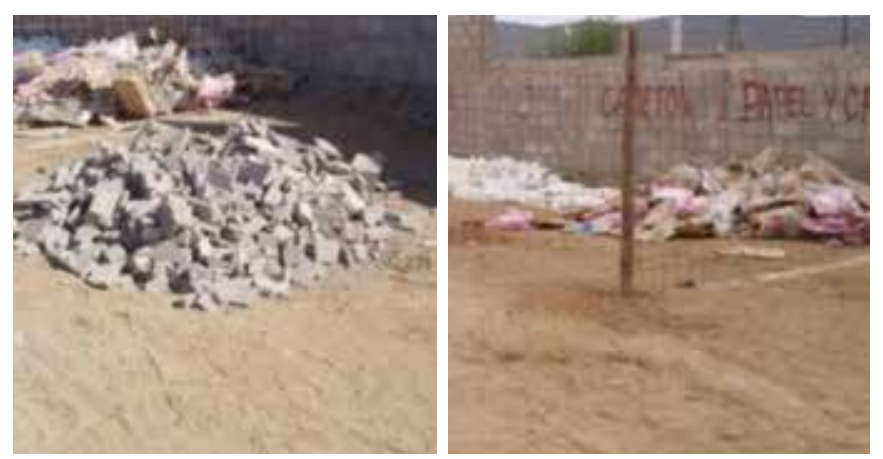

Figura 8. Áreas de disposición de residuos y/o desperdicios. 
Al personal que auxilió en la recolección y medición se capacitó para separar el material, su disposición, pesaje y registro de datos.
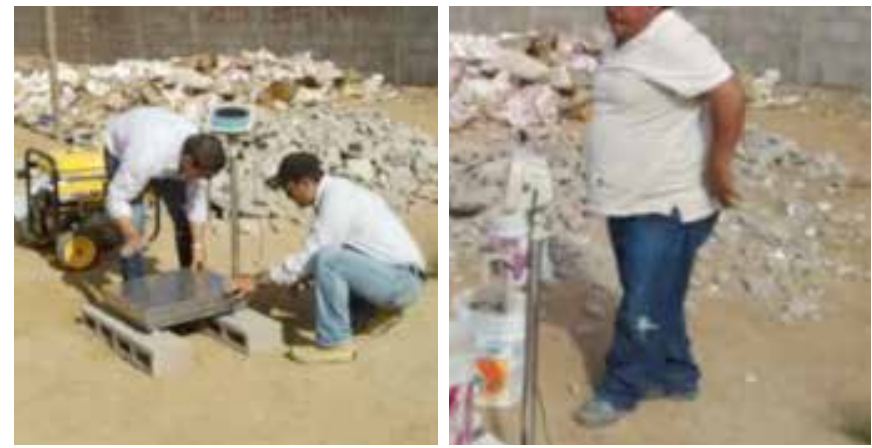

Figura 9. Instrucción del personal que recolecta y pesa los residuos y/o desperdicios.

Para los formatos de control, se capturó la información en formatos individuales; es decir, uno para cada residuo o desperdicio como block, concreto, mortero, papel y cartón o plástico y poliducto.

\section{Medición de los residuos y/o desperdicios}

Generalmente, la medida variable de los residuos y/o desperdicios es el peso, el cual se determina por la unidad de medida del material que le dio origen al residuo, los que a continuación se describen:

Concreto: Para calcular el volumen del residuo se tomó como referencia el peso y volumen que ocupa el concreto en estado seco y endurecido en un espécimen cilíndrico de $15 \mathrm{~cm}$ de diámetro por $30 \mathrm{~cm}$ de alto.

Mortero: Para calcular la cantidad de volumen de mortero se divide el peso total de su desperdicio entre el peso volumétrico del mortero en estado seco.

Block: Para determinar el número equivalente de piezas de block desperdiciadas, se dividió el peso total obtenido del residuo entre el peso de una unidad de block con dimensiones que corresponden a $0.12 \mathrm{~m} \times 0.20 \mathrm{~m} \times$ $0.40 \mathrm{~m}$.

Plástico-poliducto: Se pesó el total de desperdicio de poliducto dependiendo del diámetro; en este caso fue un solo diámetro, $1 / 2$ pulgada, el valor obtenido se dividió entre el peso por metro lineal estándar para este diámetro, obteniendo como resultado los metros lineales de poliducto desperdiciados.

Cartón-papel: Se determinó el peso del cartón y del papel.

Para el análisis económico se utilizaron los resultados obtenidos de la transformación de los residuos en sus equivalentes respectivos como materia prima y su precio de mercado en el momento del estudio.

\section{RESULTADOS}

La tabla 1 muestra los resultados totales de los residuos y desperdicios generados para las 12 viviendas, así como el estimado individual (por vivienda). La medición se realizó de manera continua, desde el inicio hasta la entrega de las viviendas

Tabla 1. Residuos generados.

\begin{tabular}{|l|c|c|}
\hline \multicolumn{1}{|c|}{ Residuos } & $\begin{array}{c}\text { Cantidad } \\
\text { total }(\mathbf{k g})\end{array}$ & $\begin{array}{c}\text { Cantidad } \\
\text { (kg/vivienda) }\end{array}$ \\
\hline Block & $2,302.43$ & 192.00 \\
\hline Concreto & $3,211.26$ & 268.00 \\
\hline Mortero & $3,215.89$ & 268.00 \\
\hline Papel y cartón & 211.70 & 17.60 \\
\hline Poliducto & 26.39 & 2.00 \\
\hline Total & $8,967.67$ & 747.60 \\
\hline
\end{tabular}

El impacto del volumen de los residuos generados se midió en términos de hacerlos equivalentes a elementos de mampostería, como si se fabricaran por primera vez, es decir, materia prima, como se muestran en la tabla 2.

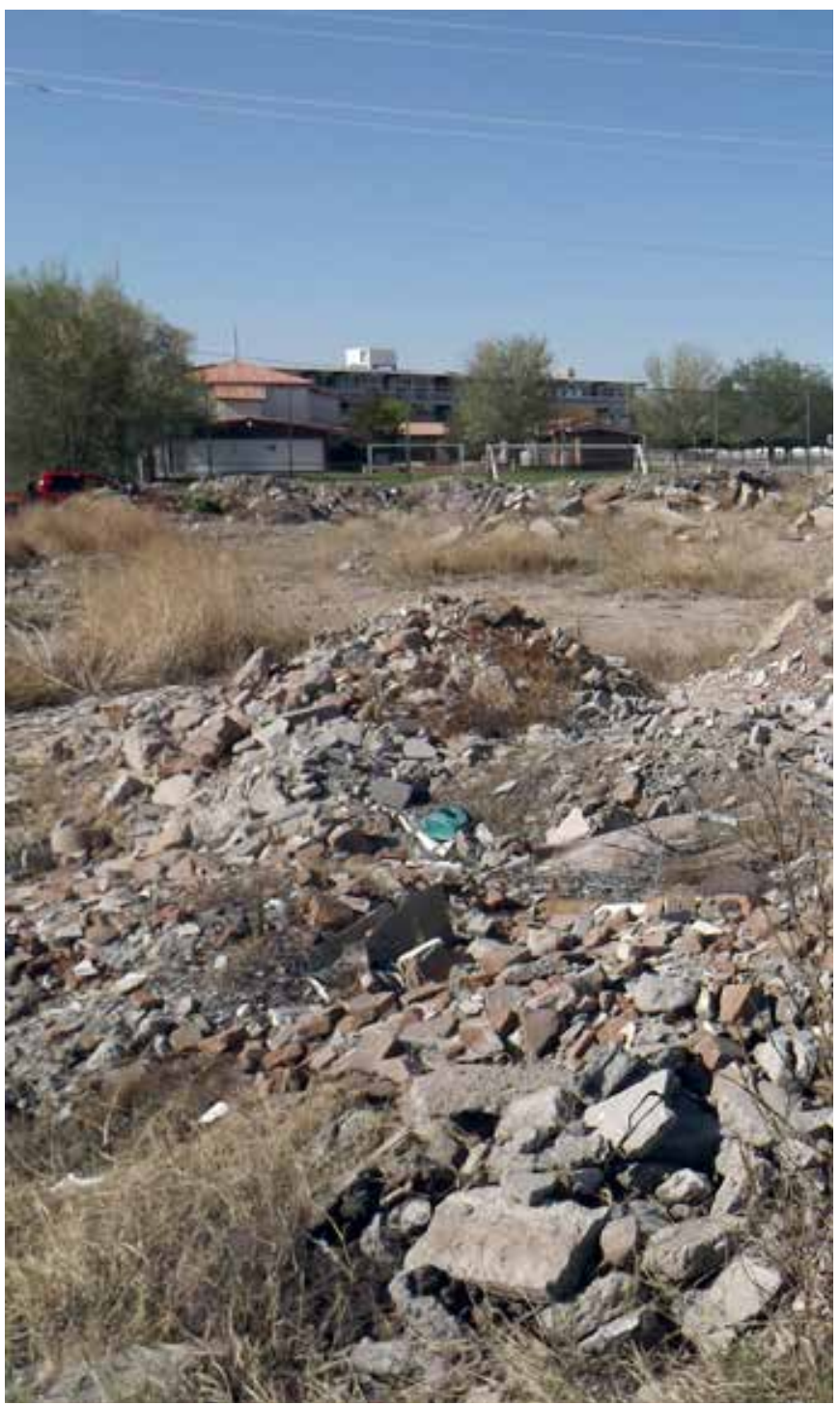


Tabla 2. Cuadro de transformación del residuo a elemento de mampostería.

\begin{tabular}{|c|c|c|c|c|c|c|c|c|c|}
\hline \multirow{2}{*}{$\begin{array}{l}\text { Residuo } \\
\text { Block }\end{array}$} & \multirow{2}{*}{$\begin{array}{c}\begin{array}{c}\text { Cantidad } \\
\text { (kg) }\end{array} \\
2,302.43\end{array}$} & \multirow{2}{*}{$\begin{array}{l}\text { Cantidad } \\
\text { (kg/ } \\
\text { vivienda) } \\
192.00\end{array}$} & \multicolumn{2}{|c|}{$\begin{array}{c}\text { Referencia } \\
\text { de unidad de } \\
\text { medida }\end{array}$} & \multicolumn{2}{|c|}{$\begin{array}{c}\text { Unidad } \\
\text { equivalente / } \\
\text { vivienda }\end{array}$} & \multicolumn{2}{|c|}{$\begin{array}{c}\text { Unidad } \\
\text { equivalente / } \\
12 \text { viviendas }\end{array}$} & \multirow{2}{*}{$\begin{array}{c}\begin{array}{c}\text { Volumen de elemento } \\
\text { de mampostería/12 } \\
\text { viviendas }\end{array} \\
16.87 \mathrm{~m}^{2} \text { de muro }\end{array}$} \\
\hline & & & 10.50 & $\mathrm{~kg} / \mathrm{pza}$ & 18.00 & pza & 219.28 & pza & \\
\hline Concreto & $3,211.26$ & 268.00 & $2,200.00$ & $\mathrm{~kg} / \mathrm{m}^{3}$ & 0.12 & $\mathrm{~m}^{3}$ & 1.46 & $\mathrm{~m}^{3}$ & $\begin{array}{l}14.6 \mathrm{~m}^{2} \text { de piso } \\
10 \mathrm{~cm} \text { espesor }\end{array}$ \\
\hline Mortero & $3,215.89$ & 268.00 & $2,150.00$ & $\mathrm{~kg} / \mathrm{m}^{3}$ & 0.12 & $\mathrm{~m}^{3}$ & 1.50 & $\mathrm{~m}^{3}$ & $\begin{array}{c}99.72 \mathrm{~m}^{2} \text { enjarre } \\
1.5 \mathrm{~cm} \text { espesor }\end{array}$ \\
\hline $\begin{array}{l}\text { Papel y } \\
\text { Cartón }\end{array}$ & 211.7 & 17.60 & 1.00 & unidad & 17.60 & $\mathrm{~kg}$ & 211.70 & $\mathrm{~kg}$ & Sin equivalencia \\
\hline Poliducto & 26.39 & 2.00 & 0.25 & $\mathrm{~kg} / \mathrm{m}$ & 9.00 & $\mathrm{~m}$ & 105.56 & $\mathrm{~m}$ & $\begin{array}{c}1.056 \text { rollos de } \\
100 \text { metros lineales }\end{array}$ \\
\hline
\end{tabular}

\begin{tabular}{|l|l|l|} 
Total & $8,967.67$ & 747.60 \\
\hline
\end{tabular}

De los valores obtenidos, se tiene que el de mayor cantidad corresponde al enjarre, seguido por el block y posteriormente el concreto. En el caso del papel y el cartón no podemos convertirlo a unidad equivalente ya que no se tienen elementos de mampostería cuya base de fabricación sean estos materiales; sin embargo, pueden ser vendidos para su reciclaje a empresas de esa industria.

El impacto económico de los volúmenes de residuos y desperdicios generados y en las cantidades de mamposterías equivalentes se determinó por costo directo de mercado sin aplicar mano de obra ni costos indirectos. La tabla 3 muestra los resultados económicos al trasformar los residuos en costo de adquisición como materia prima.

Tabla 3. Costo directo del residuo transformado a elemento de mampostería equivalente.

\begin{tabular}{|c|c|c|c|c|c|c|c|c|c|c|}
\hline \multirow{2}{*}{$\begin{array}{l}\text { Residuo } \\
\text { Block }\end{array}$} & \multirow{2}{*}{$\begin{array}{c}\text { Cantidad } \\
\text { (kg) }\end{array}$} & \multirow{2}{*}{$\begin{array}{l}\text { Cantidad } \\
\text { (kg/ } \\
\text { vivienda) } \\
192.00\end{array}$} & \multicolumn{2}{|c|}{$\begin{array}{c}\text { Referencia } \\
\text { de unidad de } \\
\text { medida }\end{array}$} & \multicolumn{2}{|c|}{$\begin{array}{c}\text { Unidad } \\
\text { equivalente / } \\
\text { vivienda }\end{array}$} & \multirow{2}{*}{$\begin{array}{c}\text { Costo/ } \\
\text { vivienda } \\
\text { del residuo } \\
\text { (\$) } \\
146.00\end{array}$} & \multicolumn{2}{|c|}{$\begin{array}{c}\text { Unidad } \\
\text { equivalente } \\
\text { total }\end{array}$} & \multirow{2}{*}{$\begin{array}{c}\begin{array}{c}\text { Costo total } \\
\text { del residuo } \\
\text { (\$) }\end{array} \\
1,754.00\end{array}$} \\
\hline & & & 10.50 & $\mathrm{~kg} / \mathrm{pza}$ & 18.00 & pza & & 219.28 & pza & \\
\hline Concreto & $3,211.26$ & 268.00 & $2,200.00$ & $\mathrm{~kg} / \mathrm{m}^{3}$ & 0.12 & $\mathrm{~m}^{3}$ & 146.00 & 1.46 & $\mathrm{~m}^{3}$ & $1,752.00$ \\
\hline Mortero & $3,215.89$ & 268.00 & $2,150.00$ & $\mathrm{~kg} / \mathrm{m}^{3}$ & 0.12 & $\mathrm{~m}^{3}$ & 125.00 & 1.50 & $\mathrm{~m}^{3}$ & $1,496.00$ \\
\hline $\begin{array}{l}\text { Papel y } \\
\text { cartón }\end{array}$ & 211.70 & 17.60 & 1.00 & $\mathrm{~kg}$ & 17.60 & kg & 26.46 & 211.70 & $\mathrm{~kg}$ & 317.50 \\
\hline Poliducto & 26.39 & 2.00 & 0.25 & $\mathrm{~kg} / \mathrm{m}$ & 9.00 & $\mathrm{~m}$ & 44.00 & 105.56 & $m$ & 528.00 \\
\hline Total & $8,967.67$ & 747.60 & & & & & 487.46 & & & $5,847.50$ \\
\hline
\end{tabular}

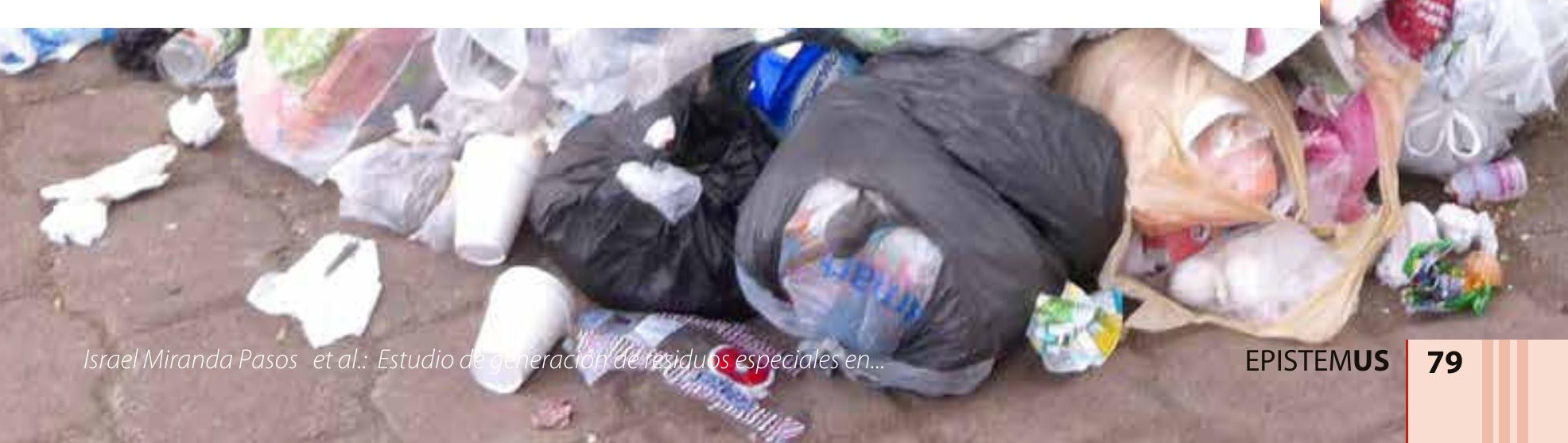




\section{CONCLUSIONES}

Los volúmenes de los cinco materiales considerados como residuos $y / 0$ desperdicios que se generaron representan cantidades considerables en términos de nuevos elementos de mampostería, es decir, para 12 viviendas de interés social representan las siguientes cantidades: $16.87 \mathrm{~m}^{2}$ de muro de block, $14.16 \mathrm{~m}^{2}$ de piso de concreto de $10 \mathrm{~cm}$ de espesor, $99.20 \mathrm{~m}^{2}$ de enjarre grueso de $1.50 \mathrm{~cm}$ de espesor, 1.05 rollos de poliducto naranja de $1 / 2$ " de diámetro. Económicamente, representan el costo directo de materiales aproximadamente de $\$ 5,847.5$ pesos, costos de mercado a la fecha de reporte.

El manejo adecuado de los materiales en la construcción es un factor importante para la disminución de la generación de residuos y desperdicios, aunado a la disminución del impacto al ambientey la menor generación de residuos que tienen que ser dispuestos en lugares especiales. Además, representa ahorros económicos en materiales, disposición de ellos y mano de obra, por lo que debe ser valorada la implementación de procesos que garanticen el control y manejo de la generación de desperdicios y/o residuos en la construcción.

\section{BIBLIOGRAFÍA}

[1]. N. Casado Martínez, et al. La enseñanza de la Arquitectura y del Medio Ambiente. Barcelona: Editorial Impresión S.A. de Litografía, 1996. Pág. 9-14. ISBN 84-89698-34-1.

[2]. E. C. Enkerlin, et al. Ciencias Ambientales y Desarrollo Sostenible. Cd. De México: Editorial International Thomson, 1997.

[3]. J. G. Henry y G. W. Heinke. Ingeniería Ambiental. Naucalpan de Juárez: Editorial Pearson Prentice Hall, 1999.

[4]. "Plan de Desarrollo Urbano Municipal 2007". Cd.
Hermosillo, Sonora: H. Ayuntamiento de Hermosillo, 2007.

[5]. ITeC, Unión Europea Fondo Social Europeo y Fundación Biodiversidad (2006) Guía general de buenas prácticas ambientales para el jefe de obra. Pp. 7-13. [En línea] Disponible: <http://itec.cat/servicios/librospdf/pdfs/ Gu\% C3\%ADa\%20general\%20de\%20buenas \% 20 pr\%C3\%A1cticas \%20ambientales \%20para\%20el\%20 jefe $\% 20$ de\%20obra ITeC 2006.pdf>

[6] J. A. Medina et al. "la situación de los residuos sólidos en México" Minimización y manejo ambiental de los residuos sólidos. Cd. De México: SEMARNAT, 2001 [En línea] Disponible< http://www2.inecc.gob.mx/publicaciones/ libros/345/sresiduos.html>

[7] F. Maña, J. M. González y A. Sagrera. Plan de Gestión de Residuos en las Obras de Construcción y Demolición. Catalunya: Instituto Tecnológico de Cataluña (ITeC) y Programa Life, Dirección General de Medio Ambiente-Comisión Europea, 2000.

[8] Diario Oficial de la Federación (2003). Ley General para la Prevención y Gestión Integral de los Residuos. [En línea] Disponible: <http://www.diputados.gob.mx/LeyesBiblio/ pdf/263_220515.pdf>

[9] Diario Oficial de la Federación (2006) Reglamento de la Ley General para la Prevención y Gestión Integral de los Residuos. [En línea] Disponible: < http://www.profepa. gob.mx/innovaportal/file/1162/1/reglamento_de_la_ley_ general_para_la_prevencion_y_gestion_in.pdf $>$

[10] NOM-161-SEMARNAT-2011."Que establece los criterios para clasificar a los residuos de manejo especial y determinar cuáles están sujetos a plan de manejo; el listado de los mismos, el procedimiento para la inclusión o exclusión a dicho listado; así como los elementos y procedimientos para la formulación de los planes de manejo". México: Diario Oficial de la Federación, 2011.

[11] Buenas Prácticas Ambientales en las Obras de Construcción (2006). Consultada el 06 de marzo de 2012. [En línea] Disponible: $<w w w . i t e c . e s>$.

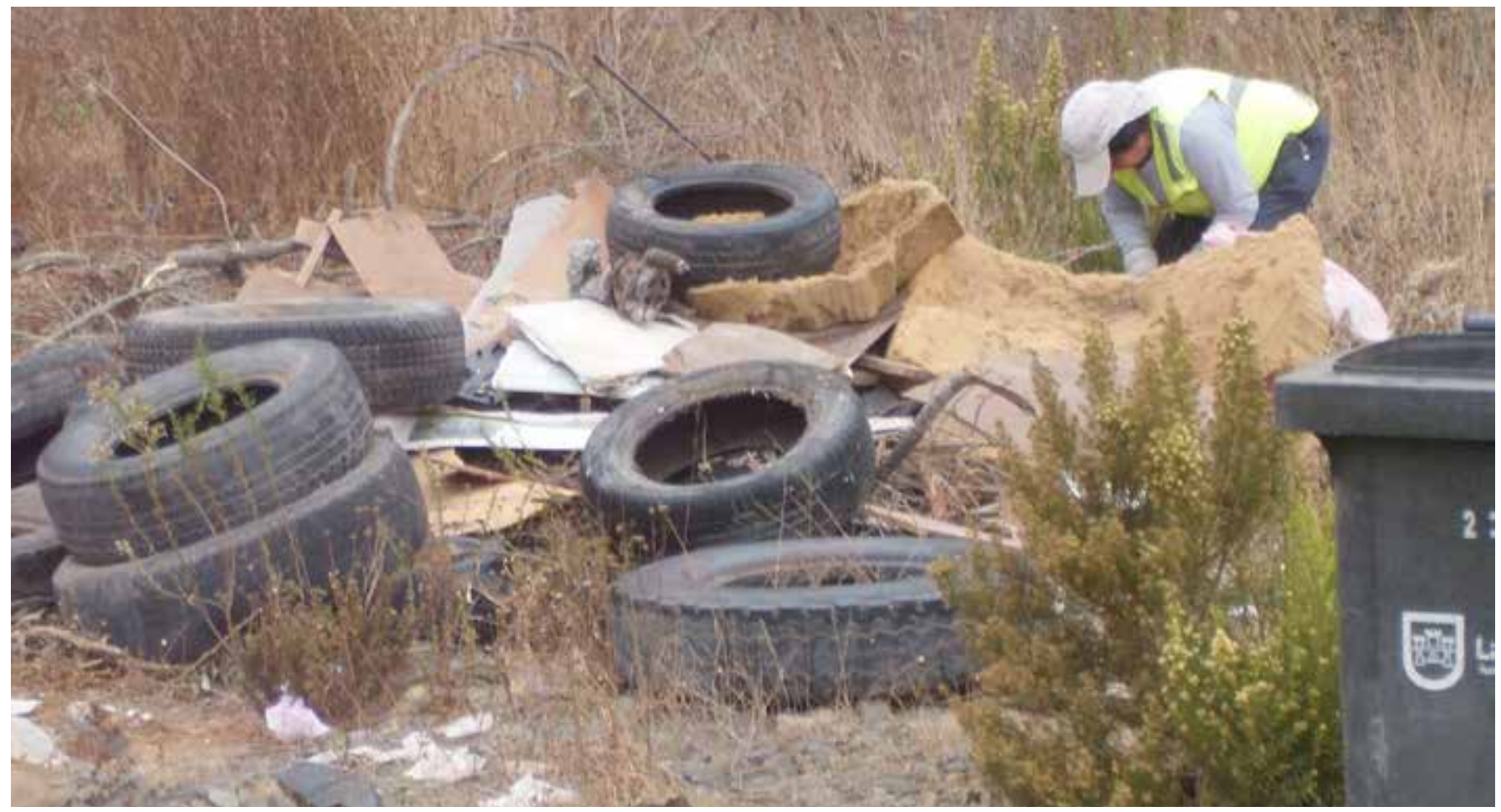

